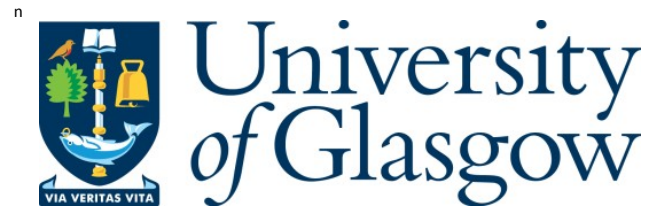

Carruthers, J. M . (2016) City of Edinburgh Council v S. Forced M arriage in Scotland: the legal response. Edinburgh Law Review, 20(1), pp. 86-94.

There may be differences between this version and the published version. Y ou are advised to consult the publisher's version if you wish to cite from it.

http://eprints.gla.ac.uk/112851/

Deposited on: 25 J anuary 2016

Enlighten - R esearch publications by members of the U niversity of Glasgow http://eprints.gla.ac.uk 


\section{City of Edinburgh Council v S. Forced Marriage in Scotland: The Legal Response}

\section{A. CHOICE OF LAW RULES PERTAINING TO ANNULMENT OF MARRIAGE}

Scots choice of law rules regarding annulment of marriage rest partly on common law and partly on the Family Law (Scotland) Act 2006. Common law principle, echoed in the 2006 Act, provides that a forum must analyse the alleged marriage defect, and classify it as pertaining to essentials or form.

\section{(1) Lack of consent as a ground of nullity of marriage in a Scots forum}

The nature and extent of free will necessary to create a valid marriage are matters of substance for decision by the parties' personal law(s). Section 38(2)(b) of the 2006 Act provides the rule on party consent, directing that the question whether a person who enters into a marriage consented to enter into it shall be determined by that person's ante-nuptial domicile. ${ }^{1}$ The rule is supplemented by section 2 of the 2006 Act, which inserts, as section 20A of the Marriage (Scotland) Act 1977, a provision on void marriages solemnised in Scotland: where a party who was capable of consenting to the marriage purported to give consent, but did so by reason only of duress or error, the marriage shall be void. Similarly, where, at the time of the marriage ceremony, a party was incapable of understanding the nature of marriage and of consenting, the marriage shall be void. ${ }^{2}$

As is well known, parties may marry, not with the Scottish requirement of free will, but rather out of a sense of family duty, if that is the pattern or expectation of their cultural background. If a court is satisfied that the threat to, or coercion of, either party to the purported marriage was sufficient to cause the pursuer's will to be overborne and to vitiate his/her consent to marry, decree of nullity will be granted. ${ }^{3}$

\section{(2) Forced marriage}

\footnotetext{
${ }^{1}$ Subject, however, to the saving in s 38(3).

${ }^{2}$ See also s 20A(4), concerning sham marriages.

3 e.g. Mahmud v Mahmud 1994 SLT 599; Mahmood v Mahmood 1993 SLT 589; Sohrab v Kahn 2002 SLT 1255; and Singh v Singh 2005 SLT 749.
} 
Forced marriage has been defined as: ${ }^{4}$

$<\mathrm{EXT}>\ldots$ a marriage in which one or both spouses do not (or, in the case of children and some adults at risk, cannot) consent to the marriage and duress is involved. Duress can include physical, psychological, financial, sexual and emotional pressure. $<$ EXT $>$

Physical pressure to marry may be constituted by threats, physical violence or sexual violence; and emotional and psychological pressure may exist where a person is made to feel that s/he is bringing shame or dishonour on his/her family.

\section{(3) Forced Marriage (Civil Protection) Act 2007}

For England and Wales, and Northern Ireland, ${ }^{5}$ the Forced Marriage (Civil Protection) Act 2007 ("the 2007 Act”) came into force on 25 November 2008. The 2007 Act inserted a new part 4A into the Family Law Act 1996 (part of the general provisions protecting against domestic violence), and sought to provide civil law protection against forced marriage in England and Wales, and Northern Ireland. The 2007 Act did not create any specific new criminal offence of forced marriage, and it was hoped that the strategy of using civil rather than criminal law measures would encourage victims to seek protection, avoiding the need in particular to report family members to the police or other authorities. The Act did not affect any other protection or assistance already available to victims of forced marriage, such as civil remedies under the Protection from Harassment Act 1997, or the law of marriage. ${ }^{6}$

\section{(4) Forced Marriage etc. (Protection and Jurisdiction) (Scotland) Act $2011^{7}$}

The 2007 Act has no application to Scotland. For Scotland, legal protection against being forced into marriage has been afforded to "protected persons" by the Forced Marriage etc. (Protection and Jurisdiction) (Scotland) Act 2011 (“the 2011 Act”). The 2011 Act was passed by the Scottish Parliament on 22 March 2011 to provide a specific civil remedy for individuals who are threatened with forced marriage, and for persons already in such a

\footnotetext{
${ }^{4}$ Scottish Government, Forced Marriage - Statutory Guidance (Revised)(2014) 37. For England and Wales, see Family Law Act 1996 s 63A(4).

${ }^{5}$ In respect of which, see $\operatorname{Re} G$ and D (Minors) [2011] NICA 55.

${ }^{6}$ Family Law Act 1996 s 63R.

${ }^{7}$ See also Forced Marriage etc. (Protection and Jurisdiction) (Scotland) Act 2011 (Commencement) Order 2011 (SSI 2011/352).
} 
marriage. The Act, which came into force on 28 November 2011, closely resembles the 2007 Act.

Part 1 of the 2011 Act enables the Court of Session or sheriff court to make a forced marriage protection order ("FMPO”) for the purposes of protecting a person (adult or child) from being forced into marriage without their free and full consent; and to protect a person who has been forced to enter into marriage without such consent. ${ }^{8}$ A person (“A”) is regarded as forced into a ceremony of marriage if another person (“ $\mathrm{B}$ ”) forces A to enter into a ceremony of marriage without A's free and full consent. ${ }^{9}$ The ceremony may be religious or civil, can take place in Scotland or elsewhere, and need not be legally binding as a marriage under the law of Scotland or any other place. ${ }^{10}$

$<$ EXT $>$ Section 1(2) of the 2011 Act is very widely drawn and simply provides that:

In deciding whether to make such an order and, if so, what order to make, the court must have regard to all the circumstances including the need to secure the health, safety and well-being of the protected person. $<\mathrm{EXT}>$

By section 1(6), “force” is defined as including coercion, by physical, verbal or psychological means, threatening conduct, or harassment; and knowingly taking advantage of a person's incapacity to consent to marriage or to understand the nature of the marriage. The conduct which forces a person to marry need not necessarily be directed against them personally. ${ }^{11}$ A FMPO may be sought by the "protected person" or any relevant third party, ${ }^{12}$ or may be granted ex proprio motu by the court, ${ }^{13}$ and by section 2 may contain such prohibitions, restrictions or requirements, and other terms, as the court considers appropriate for the purposes of the order. ${ }^{14}$ Notably, the terms of the order may relate to conduct outside, as well

\footnotetext{
${ }^{8}$ Section $1(1)$.

${ }^{9}$ Section $1(4)$.

${ }^{10}$ Section 14.

${ }^{11}$ Section 1(5).

${ }^{12}$ Section 3(1).

${ }^{13}$ Section 4.

${ }^{14}$ Section 2(3). A FMPO may require, inter alia, a person to take the protected person to a place of safety designated in the order, or to refrain from violent, threatening or intimidating conduct (whether against the protected person or any other person), or to disclose, if known, the whereabouts of such a person.
} 
as, or instead of, conduct within Scotland. ${ }^{15}$ The burden of proof lies on an applicant to show, on the balance of probabilities, that a FMPO is required.

Importantly, section 9 provides that any person who, knowingly and without reasonable excuse, breaches a FMPO commits an offence and is subject to criminal penalties. The Act does not affect the law of marriage, ${ }^{16}$ and so any matrimonial remedy to be sought by the protected person must be pursued separately. ${ }^{17}$

\section{(5) The Anti-Social Behaviour, Crime and Policing Act 2014}

Since 30 September $2014,{ }^{18}$ forcing someone into marriage has been a criminal offence in Scotland by dint of section 122 of the Anti-Social Behaviour, Crime and Policing Act 2014 (“the 2014 Act”). ${ }^{19}$ A person commits an offence if s/he (a) uses violence, threats or any other form of coercion for the purpose of causing another person to enter into a marriage, and (b) believes, or ought reasonably to believe, that the conduct may cause the other person to enter into the marriage without free and full consent. ${ }^{20}$ Moreover, a person commits an offence if s/he practises any form of deception with the intention of causing another person to leave the UK, and intends the other person to be subject to conduct outside the UK that is an offence under section 122(1). ${ }^{21}$

This criminal provision is intended to add another layer of protection for those at risk of forced marriage, and sits alongside existing protections in the 2011 Act and elsewhere. Victims of forced marriage still may invoke civil law remedies, including applying for a FMPO, but this can be done now in tandem with criminal proceedings under the 2014 Act. Notably, the consent of a victim of forced marriage is not a prerequisite for criminal proceedings in Scotland; the views of the victim are only one factor for the prosecution service to consider when deciding whether or not to bring criminal proceedings, and the decision in any case to prosecute, or not, must take account of public interest considerations.

\footnotetext{
${ }^{15} \mathrm{cf}$. the 2007 Act, which contains no conflict of laws provisions as such, but is intended to have extra-territorial import insofar as the terms of a FMPO may relate not only to conduct within England and Wales, but also, or instead of, to conduct outside England and Wales, e.g. in the face of fear of forced marriage taking place abroad: Family Law Act 1996 s 63B(2)(a). ${ }^{16}$ Section $12(2)(\mathrm{g})$.

${ }^{17}$ See e.g. under the 2007 Act in England, Re P (Forced Marriage) [2010] EWHC 3467 (Fam); [2011] 1 F.L.R. 2060.

${ }^{18}$ SSI 2014/221 art 2.

${ }^{19}$ Likewise, under the 2014 Act, forced marriage was made a criminal offence in England and Wales per s 121.

${ }^{20}$ Section 122(1).

${ }^{21}$ Section $122(3)$.
} 


\section{B. CITY OF EDINBURGH COUNCIL V S}

The first reported case on interpretation and application of the 2011 and 2014 Acts called in March 2015 before Sheriff W A Sheehan in Edinburgh, and involved consideration of what the sheriff deemed to be "a novel area of law and a complex factual matrix". ${ }^{23}$ The Council applied as a relevant third party, ${ }^{24}$ under section 1 of the 2011 Act, for a FMPO in relation to a 15 year old girl, AS (“the protected person”, born 31 January $2000^{25}$ ). The local authority sought to have the court ordain, for an indefinite period, that AS's parents, MS and NS (AS's father and mother, the first and second respondents, respectively) refrain from conduct with a view to forcing AS to enter into a marriage. Auxiliary orders were sought to prevent AS's parents removing her from the UK; requiring AS to submit her passport to the court; and permitting social workers to secure access to AS in order to monitor her wellbeing, all to have effect until AS attained 21 years. The Council averred that relevant risk to AS could be inferred from evidence of the respondents' behaviour in relation to AS's siblings, and materially, their marriages. Notably, AS opposed the granting of the FMPO.

Sheriff Sheehan dismissed the application. Significantly, although no evidence had been adduced to show either that a marriage had been planned or that a putative spouse had been identified, the sheriff noted that a literal interpretation of section 1 of the 2011 Act, requiring the court to establish the existence of an actual marriage planned for the protected person: ${ }^{26}$

$<$ EXT $>$.. would thwart the policy intention of the legislation. Many applications would fail where applicants were unable to adduce evidence of a planned marriage but where otherwise the evidence clearly pointed to there being a requirement to protect the protected person from an attempt at forced marriage being made. $<$ EXT $>$

It is noteworthy that the first reported case on interpretation of the 2011 Act should result in dismissal of the application for a FMPO.

\footnotetext{
222015 SLT (Sh Ct) 69.

${ }^{23}$ Para 95

${ }^{24} 2001$ Act ss 3(1)(b) and (7)(a).

${ }^{25}$ Aged 13 when the proceedings were raised.

${ }^{26}$ Para 82. The rubric, as reported at para 3, is misleading in this important regard.
} 


\section{(1) Demonstrating risk to the "protected person"}

The Council averred that there was a risk that AS would be forced into marriage or that an attempt would be made by her parents to force her into marriage. The basis upon which the sheriff was asked to conclude that a FMPO was required under section 1(2) of the 2011 Act to secure the health, safety and well-being of AS was based primarily on an assessment of the evidence of the circumstances surrounding the marriages of her siblings. Scottish Government statutory guidance on forced marriage ${ }^{27}$ urges professionals to be alert to any family history of the putative protected person's siblings being forced to marry. The referral of AS, triggered by her sister, KS (born 5 April 1991), was made in 2012 to Edinburgh City Council's social work department due to her concern regarding the possibility of AS's being forced into marriage. In the sheriff's view, “[t]he cornerstone of the applicant's case is the assertion that KS was forced to marry [her second cousin] by the respondents.”28 KS alleged that her parents had forced her into marriage four years previously when she was aged 16 years. The respondents denied the allegation, averring that KS married her second cousin in 2008 of her own free will, and that she determined the timing of her wedding, which they arranged and paid for at her request. Sheriff Sheehan, noting that KS was a vulnerable young woman, estranged from her family, concluded that there was no supporting evidence of KS's account of events. ${ }^{29}$

Separately, evidence was led of two other prior incidents involving an elder sister, FS (born 23 May 1985), when FS sought police assistance regarding her parents purportedly arranging her marriage against her will. The respondents, however, averred that they had respected FS's decision not to marry, and that no pressure was brought to bear upon her. Again, Sheriff Sheehan found that there was no reliable and credible evidence that the respondents had attempted to force FS to marry. ${ }^{30}$ Although AS's referral was instigated by her sister, KS, and the Council alleged a history of forced marriage and threatening conduct within the wider family, impacting therefore on the assessment of risk to AS, the Sheriff held

\footnotetext{
${ }^{27}$ Produced in line with 2011 Act s 11. See Scottish Government, Forced Marriage Statutory Guidance (Revised)(2014); Scottish Government, Scottish Statutory Guidance Supplementary Guidance (2014), available at http://www.gov.scot/Resource/0046/00462181.pdf; and Scottish Government, Multi-Agency Practice Guidelines: Preventing and Responding to Forced Marriage (2014), available at http://www.gov.scot/Resource/0046/00460555.pdf.

${ }^{28}$ Para 33.

${ }^{29}$ Para 37.

${ }^{30}$ Para 30.
} 
that there was no evidence to support the contention that any attempt was made to force any of AS’s siblings into marriage. ${ }^{31}$

In cases of this nature, witnesses are subject to particular pressures "including distress, anxiety, pressure, shame or family honour”. ${ }^{32}$ It is inevitable in such cases that conflicting evidence will be given, and that an applicant will give a different account of events than will the respondents, and possibly also than the putative protected person. The assessment of credibility and reliability of witnesses, and in turn the assessment of risk to the putative protected person, is particularly difficult.

\section{(2) Relevant factors in the assessment of risk}

(a) Warning signs

Over the 15 months following AS's referral to the social work department, enquiries were conducted, in line with Scottish Government statutory guidance, with relevant professionals being on the alert for "warning signs", 33 none of which, however, had been observed in relation to $\mathrm{AS}^{34}$

(b) The protected person's position

AS opposed the granting of the FMPO. When deciding whether or not to grant a FMPO, and in ascertaining the protected person's well-being, a court must, in particular, have regard to the person's wishes and feelings (as far as they are reasonably ascertainable) as the court considers appropriate on the basis of the person's age and understanding. ${ }^{35}$ The court must take account of the fact that the wishes and feelings of a child or young person may have been stated against a background of incomplete understanding of risks. ${ }^{36}$ AS had had regular contact with social work professionals and advocacy workers, including on a private one-toone basis - apparently beyond the reach of family influence - and had instructed her own solicitor to oppose the grant of the FMPO. In her view, there was no need for the order to be

\footnotetext{
${ }^{31}$ Paras 26-30, 32-46, 51-57 and 88-90.

32 Para 37.

${ }^{33}$ Para 5; e.g. changes in the protected person's attire from western to more traditional clothing; signs of depression or isolation; absences from school; a decline in performance or punctuality at school; withdrawal from extracurricular activities; and social isolation within a peer group.

${ }^{34}$ Para 65.

352011 Act s 1(3)

${ }^{36}$ Para 87.
} 
granted, and she regarded the interim order which had been granted ex parte as unnecessary, unwelcome and intrusive. $^{37}$

(c) Awareness of a culture of familial pressure

The Council argued that, when assessing the risk of the protected person being forced into marriage, the court should consider evidence of a culture of forced marriage in the wider (paternal) family. It is important for the court to distinguish between a culture of arranged marriages, and evidence of forced marriage. ${ }^{38}$ Although arranged and forced marriages are on the same spectrum - insofar as a forced marriage is always an arranged one - the majority of arranged marriages are entered into by parties on an entirely voluntary basis, and without third party duress or coercion. The question of family pressure/influence is extremely delicate.

\section{(3) Implications of the grant of a FMPO - human rights dimension and criminal penalties}

A court requires to consider whether the grant of a FMPO would be proportionate with regard to the ECHR in relation to the rights enjoyed under article 8 (right to respect for private and family life), not only of the protected person, but also the respondents, and in particular, to consider the impact of any order on parties' art.8 rights. Sheriff Sheehan noted that the orders, if granted, would have a significant impact on AS's private life insofar as she would be under social work supervision until she attained 21 years and would be required to disclose information to social workers regarding her private life, and to seek social workers' approval for any travel within the UK. ${ }^{39}$

Where interference with article 8 rights is necessary to protect a person's article 12 right to marry, it is warranted in terms of article 8(2) as being necessary for the prevention of disorder or crime, the protection of health or morals or for the protection of rights and freedoms of others. ${ }^{40}$ In the case at hand, however, the sheriff concluded that the granting of the orders sought would infringe significantly upon the article 8 rights of both AS and her parents.

\footnotetext{
${ }^{37}$ Para 62.

${ }^{38}$ Para 47.

${ }^{39}$ Para 76.

${ }^{40}$ Para 78. cf. Re A (Forced Marriage: Special Advocates) [2010] EWHC 2438 (Fam); [2011] 2 WLR 1027; [2012] Fam 102
} 
Separately, and ironically, the availability of section 122 of the 2014 Act provides what was considered by the sheriff to be a proportionate alternative to the grant of a FMPO. ${ }^{41}$ As stated above, the effect of the 2014 Act is that criminal penalties are available even in the absence of a FMPO. In the instant case, the sheriff did not accept the applicant's submission that the orders sought were necessary in order to protect AS, nor that they were proportionate in all the circumstances of the case.

\section{CONCLUSION}

In assessing risk to the protected person, it is difficult to know how interventionist the authorities, including the courts, ought to be. The 2011 Act does not incorporate guidance, such as is contained in section 11(7) of the Children (Scotland) Act 1995, to the effect that an order should be made only when it is better for the child that an order be made than that none be made at all. How serious ought the risk be to the putative protected person before the court will grant a FMPO? The degree of risk must be put in the balance alongside the likely repercussions for the protected person, and for the respondents, if an order is made. Sheriff Sheehan rejected the argument that in order to grant a FMPO the court must be satisfied of "a genuine and serious risk" or that the risk must be "substantial” or of "a very high level”. Rather, “[a]ll that is required is for the court to find that on the balance of probabilities the evidence supports the granting of orders which are needed to protect AS from being forced into a marriage and that the orders would secure her health, safety and wellbeing. $^{42}$

Although, importantly, Sheriff Sheehan remarked that "[a] literal interpretation of s.1 requiring evidence of an actual marriage would thwart the policy intention of the legislation", ${ }^{43}$ nonetheless, in view of the outcome in this case, it seems unlikely in practice that sufficient risk to the putative protected person will be shown if no putative spouse has been identified or there is no clear evidence that an actual marriage has been planned for her/him, a fortiori if the putative protected person is opposed to the grant of a FMPO. The 2011 Act empowers relevant third parties to act on a vulnerable person's behalf where s/he is not at liberty so to do, but it is extremely difficult for a court to act against the

\footnotetext{
${ }^{41}$ So too Children's Hearing (Scotland) Act 2011 s 67(2)(q).

${ }^{42}$ Para 83.

${ }^{43}$ Para 82.
} 
(seemingly) unequivocal and sustained wishes of an apparently mature and articulate teenager who, as well as being of an age and maturity sufficient to assess the risk of forced marriage, is old and mature enough to know what will be, for her, the adverse consequences of (inevitable?) estrangement from her family.

City of Edinburgh Council v S shows that, well-intentioned though the 2011 Act is in seeking to provide protective remedies for vulnerable individuals, the practical and evidentiary difficulties inherent in securing the remedy of FMPO are not to be underestimated.

$J$ M Carruthers University of Glasgow 